UMTRI-2005-38

\title{
DISTANCE PERCEPTION WITH A CAMERA-BASED REAR VISION SYSTEM IN ACTUAL DRIVING
}

\author{
Michael J. Flannagan \\ Mary Lynn Mefford
}

December 2005 


\title{
DISTANCE PERCEPTION WITH A CAMERA-BASED REAR VISION SYSTEM IN ACTUAL DRIVING
}

\author{
Michael J. Flannagan \\ Mary Lynn Mefford
}

The University of Michigan Transportation Research Institute Ann Arbor, Michigan 48109-2150 U.S.A.

Report No. UMTRI-2005-38

December 2005 
Technical Report Documentation Page

\begin{tabular}{|c|c|c|c|c|}
\hline $\begin{array}{l}\text { 1. Report No. } \\
\text { UMTRI-2005-38 }\end{array}$ & 2. Government Accession No. & \multicolumn{3}{|c|}{ 3. Recipient's Catalog No. } \\
\hline \multirow{2}{*}{\multicolumn{2}{|c|}{$\begin{array}{l}\text { 4. Title and Subtitle } \\
\text { Distance Perception with a Camera-Based Rear Vision } \\
\text { System in Actual Driving }\end{array}$}} & \multicolumn{3}{|c|}{$\begin{array}{l}\text { 5. Report Date } \\
\text { December } 2005\end{array}$} \\
\hline & & \multicolumn{3}{|c|}{$\begin{array}{l}\text { 6. Performing Organization Code } \\
302753\end{array}$} \\
\hline \multicolumn{2}{|c|}{$\begin{array}{l}\text { 7. Author(s) } \\
\text { Flannagan, M.J., Mefford, M.L. }\end{array}$} & \multicolumn{3}{|c|}{$\begin{array}{l}\text { 8. Performing Organization Report No. } \\
\text { UMTRI-2005-38 }\end{array}$} \\
\hline \multirow{2}{*}{\multicolumn{2}{|c|}{$\begin{array}{l}\text { 9. Performing Organization Name and Address } \\
\text { The University of Michigan } \\
\text { Transportation Research Institute } \\
\text { 2901 Baxter Road } \\
\text { Ann Arbor, Michigan 48109-2150 U.S.A. }\end{array}$}} & \multicolumn{3}{|c|}{ 10. Work Unit no. (TRAIS) } \\
\hline & & \multicolumn{3}{|c|}{ 11. Contract or Grant No. } \\
\hline \multirow{2}{*}{\multicolumn{2}{|c|}{$\begin{array}{l}\text { 12. Sponsoring Agency Name and Address } \\
\text { The University of Michigan } \\
\text { Industry Affiliation Program for } \\
\text { Human Factors in Transportation Safety }\end{array}$}} & \multicolumn{3}{|c|}{ 13. Type of Report and Period Covered } \\
\hline & & \multicolumn{3}{|c|}{ 14. Sponsoring Agency Code } \\
\hline \multicolumn{5}{|c|}{$\begin{array}{l}\text { 15. Supplementary Notes } \\
\text { The Affiliation Program currently includes Autoliv, Avery Dennison, Bendix, BMW, } \\
\text { Bosch, Com-Corp Industries, DaimlerChrysler, DBM Reflex, Decoma Autosystems, } \\
\text { Denso, Federal-Mogul, Ford, GE, General Motors, Gentex, Grote Industries, Guide } \\
\text { Corporation, Hella, Honda, Ichikoh Industries, Koito Manufacturing, Lang-Mekra } \\
\text { North America, Magna Donnelly, Muth, Nissan, North American Lighting, OLSA, } \\
\text { OSRAM Sylvania, Philips Lighting, PPG Industries, Renault, Schefenacker } \\
\text { International, Sisecam, SL Corporation, Stanley Electric, Toyoda Gosei North America, } \\
\text { Toyota Technical Center USA, Truck-Lite, Valeo, Visteon, 3M Personal Safety } \\
\text { Products, and 3M Traffic Safety Systems. } \\
\text { Information about the Affiliation } \\
\text { http://www.umich.edu/ Program industry/ is }\end{array}$} \\
\hline \multicolumn{5}{|l|}{ 16. Abstract } \\
\hline \multicolumn{5}{|c|}{$\begin{array}{l}\text { This study examined drivers' perceptions of distance to a rearward vehicle while } \\
\text { using a camera-based rear vision system in actual driving conditions. Participants } \\
\text { drove an instrumented car equipped with conventional rearview mirrors and with a } \\
\text { camera rear vision system. Using various configurations of these rear vision systems, } \\
\text { they observed the approach of an overtaking car and indicated the last moment at which } \\
\text { it would be safe to initiate a lane-change maneuver in front of it. Their judgments were } \\
\text { strongly affected by the type of display used to observe the overtaking car. The longest } \\
\text { distances were obtained with the camera-based display at unit magnification. Distances } \\
\text { were substantially shorter with the conventional mirror and with the camera-based } \\
\text { display at } 0.5 \text { magnification. These results are consistent with results from an earlier } \\
\text { study conducted under static conditions. }\end{array}$} \\
\hline $\begin{array}{l}\text { 17. Key Words } \\
\text { driving, on-road, rear visi } \\
\text { rearview mirrors, distance p }\end{array}$ & eption & & $\begin{array}{l}\text { 18. Distribution St } \\
\text { Unlimited }\end{array}$ & \\
\hline $\begin{array}{l}\text { 19. Security Classification (of this report) } \\
\text { None }\end{array}$ & $\begin{array}{l}\text { 20. Security Classification (of this pac } \\
\text { None }\end{array}$ & & $\begin{array}{l}\text { 21. No. of Pages } \\
14\end{array}$ & 22. Price \\
\hline
\end{tabular}




\section{ACKNOWLEDGMENTS}

Appreciation is extended to the members of the University of Michigan Industry Affiliation Program for Human Factors in Transportation Safety for support of this research. The current members of the Program are:

\begin{tabular}{|c|c|}
\hline Autoliv & Lang-Mekra North America \\
\hline Avery Dennison & Magna Donnelly \\
\hline Bendix & Muth \\
\hline BMW & Nissan \\
\hline Bosch & North American Lighting \\
\hline Com-Corp Industries & OLSA \\
\hline DaimlerChrysler & OSRAM Sylvania \\
\hline DBM Reflex & Philips Lighting \\
\hline Decoma Autosystems & PPG Industries \\
\hline Denso & Renault \\
\hline Federal-Mogul & Schefenacker International \\
\hline Ford & Sisecam \\
\hline GE & SL Corporation \\
\hline General Motors & Stanley Electric \\
\hline Gentex & Toyoda Gosei North America \\
\hline Grote Industries & Toyota Technical Center, USA \\
\hline Guide Corporation & Truck-Lite \\
\hline Hella & Valeo \\
\hline Honda & Visteon \\
\hline Ichikoh Industries & 3M Personal Safety Products \\
\hline Koito Manufacturing & 3M Traffic Safety Systems \\
\hline
\end{tabular}




\section{Contents}

ACKNOWLEDGMENTS $\ldots \ldots \ldots \ldots$




\section{INTRODUCTION}

Camera-based systems for indirect vision around vehicles have been anticipated and discussed for many years (e.g., Kelley \& Prosin, 1969). Recently, such systems have come into reasonably common use for low-speed maneuvers, particularly backing. It seems likely that camera-based systems will soon also be used for other, more perceptually demanding driving tasks, such as high-speed lane changes and merges. In those tasks, drivers' judgments about the distances to other vehicles can be important. That has been the main reason for concern about the possible effects of convex and aspheric rearview mirrors (e.g., Flannagan, 2000). In several recent studies, we have tried to outline the factors that may affect distance judgments in camera-based systems. Those studies have primarily used procedures in which the observer's vehicle is stationary and only a stimulus vehicle is moving. The present study was designed to test some of the conditions from the earlier studies in more realistic conditions; it was performed on a public road with both the observer's vehicle and the stimulus vehicle moving.

Practical experience with judging distance in camera-based driving displays is limited, and the possible perceptual differences between judging distance in such displays and in traditional rearview mirrors are many. Perhaps most obviously, video displays lack useful stereoscopic cues. In a recent study, based on a review of the literature and on the results of a new experiment, we concluded that the lack of stereoscopic information was not likely to cause a practical problem for the use of camera-based displays in driving (Flannagan, Sivak, \& Simpson, 2001). However, the possible consequences of the stereoscopic cues that are present in video displays (i.e., the entire scene is at the same distance from the driver, and very close) are far from fully understood.

Because video displays present images that are in fact very close to a driver, the differences in eye-to-display distance that normally exist across drivers-or within a single driver making normal head movements - can be expected to cause substantial differences in the visual angles subtended by images on the display, which may in turn cause differences in distance judgments. Data from a recent study (Flannagan, Sivak, \& 
Mefford, 2002) indicated that eye-to-display distance did in fact influence distance judgments made with a video display, whether differences in distance corresponded to the different lines of sight from a driver's left-of-center position to displays on the right and left of a passenger car or to adjustments in the front-to-rear position of the driver's seat. The distances to the images that a driver sees in a planar rearview mirror are normally very long relative to the eye-to-mirror distance: They are the same as the distances to the actual objects along the reflected lines of sight. Differences in eye-todisplay distance that are large enough to affect distance judgments in a video display are therefore not likely to affect distance judgments in a rearview mirror, and that is in fact what was found.

Table 1 shows the means and standard deviations for eye-to-mirror distances from a sample of drivers in passenger cars (Reed, Lehto, \& Flannagan, 2000), along with the ratios of distances two standard deviations above the mean to distances two standard deviations below the mean. These differences should not affect distance judgments in planar mirrors, but if variation in eye-to-display distances with video systems were comparable to this variation in eye-to-mirror distances, the consequences for distance judgments could be large enough to be of concern.

Table 1. Means and standard deviations of eye-to-mirror distances in passenger cars (Reed et al., 2000). The ratios are for distances two standard deviations above the mean to distances two standard deviations below the mean.

\begin{tabular}{|l|c|c|c|}
\hline \multicolumn{1}{|c|}{ Mirror } & Mean $(\mathrm{mm})$ & S.D. $(\mathrm{mm})$ & Ratio \\
\hline \hline Driver side & 778 & 58 & 1.35 \\
\hline Center & 515 & 54 & 1.53 \\
\hline Passenger side & 1334 & 65 & 1.22 \\
\hline
\end{tabular}

There is also evidence that video displays may differ from rearview mirrors in the effect that the frame of a display or mirror has on judgments of the distances of objects (Flannagan et al., 2002; Flannagan \& Sivak, 2003). When an image was presented at the same angular size in video displays that differed in overall angular size, the object was judged closer when seen in the display with smaller angular size (in which it filled a 
greater fraction of the screen). In rearview mirrors, this effect was either absent or greatly reduced.

In one of our earlier studies (Flannagan et al., 2002), we asked participants to make distance judgments to rearward vehicles that were seen in either rearview mirrors or video displays. For conditions in which the image sizes of the rearward vehicles were the same, the distance estimates were substantially higher in the mirrors (by 25\%). This was unexpected, and we had no fully satisfying explanation for it. Speculatively, it could be ascribed to a strategy of being conservative with an unfamiliar system (i.e., the participants might have biased their estimates toward shorter distances, which would imply greater perceived risk in traffic maneuvers, with the video system). Alternatively, it could have been a consequence of the framing effect described above. (The horizontal angular sizes of the mirrors were somewhat larger than the angular sizes of the video displays.)

The present study was designed to further investigate how drivers judge distance with camera-based rear vision systems, and to partially replicate our earlier work in fully dynamic traffic conditions. Participants drove an instrumented car equipped with a camera rear vision system and with conventional rearview mirrors on a public road. The rear vision system used a display mounted on the instrument panel to present a view similar to that available in the exterior, driver-side rearview mirror. The main experimental task for the participant was to make a decision about the safety of a possible lane-change maneuver in front of an overtaking car, a task that has been used in various versions to assess drivers' perception of distance and speed in rearview mirrors (e.g., Bowles, 1969; Burger et al., 1980; Fisher \& Galer, 1984; Mortimer, 1971; Mortimer \& Jorgeson, 1974; Walraven \& Michon, 1969). The participant observed the approach of the overtaking car and indicated the last moment at which it would be safe to initiate a lane-change maneuver in front of it. (They did not actually execute the maneuver.) The participant observed the approach in one of three display conditions: the conventional driver-side rearview mirror, the camera-based display with unit magnification, and the camera-based display with 0.5 magnification (i.e., minification). 


\section{METHOD}

\section{Participants}

There were 12 participants, six in a younger group (from 21 to 30 years old with a mean of 24.2) and six in an older group (from 61 to 79 with a mean of 71.0). There were three males and three females in each age group. All participants were licensed and active drivers. They were paid for their participation.

\section{Mirrors and Camera System}

The participant's car had a typical set of rearview mirrors: a planar left exterior mirror, a planar center interior mirror, and a convex right exterior mirror. A video camera was mounted on the left front fender as shown in Figure 1. It was slightly lower than the left exterior mirror and toward the front of the vehicle so that its vantage point would be very close to the virtual eye point of the driver when using the left mirror. The camera was equipped with a zoom lens with two positions, one that yielded an image of approximately the same magnification as the left mirror (i.e., unit magnification), and one that yielded an image half that large (i.e., 0.5 magnification). Magnification was measured in terms of the angular sizes of images from a single eye position that was meant to approximately represent the range of eye positions of all of the participants. An active matrix LCD video panel was mounted inside the cabin, on the center of the dashboard, as shown in Figure 2. This position was chosen so that the display would be about the same visual angle from the straight ahead as the left mirror, but far from that mirror, and reasonably far from the other two mirrors. Participants could therefore look selectively at either the left rearview mirror or the LCD display without getting a good view of the rearward scene from the alternative mirrors or display. The video display reversed right and left, thus producing images with spatial layouts consistent with what is seen in rearview mirrors. 


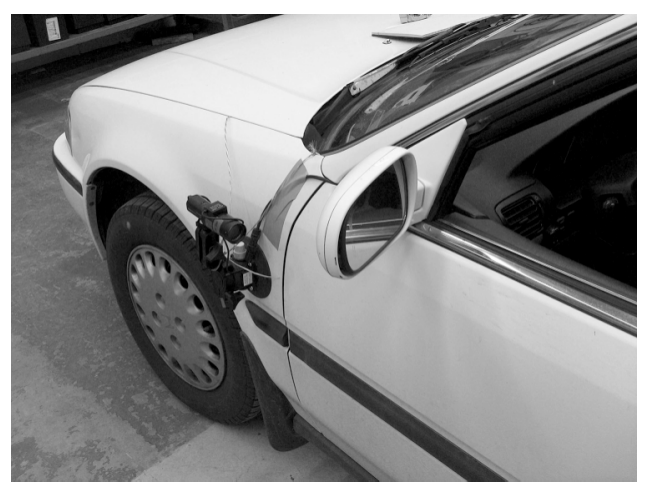

Figure 1. The camera, mounted just below and in front of the left mirror.

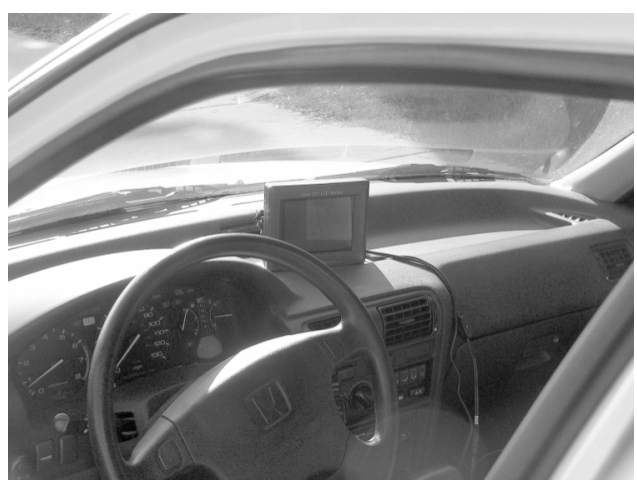

Figure 2. The video display, mounted in the middle of the dashboard.

\section{Route}

The experiment was conducted on a straight, approximately level section of a two-way, four-lane arterial road that was oriented north-south. The section used for the study was about $0.8 \mathrm{~km}$ long, with no traffic control devices. At each end of the section used, there were side streets that allowed the vehicles to pull off and turn around easily. The speed limit was 35 miles per hour $(56 \mathrm{~km} / \mathrm{hr})$ throughout the section used. Part of the road is shown in Figure 3.

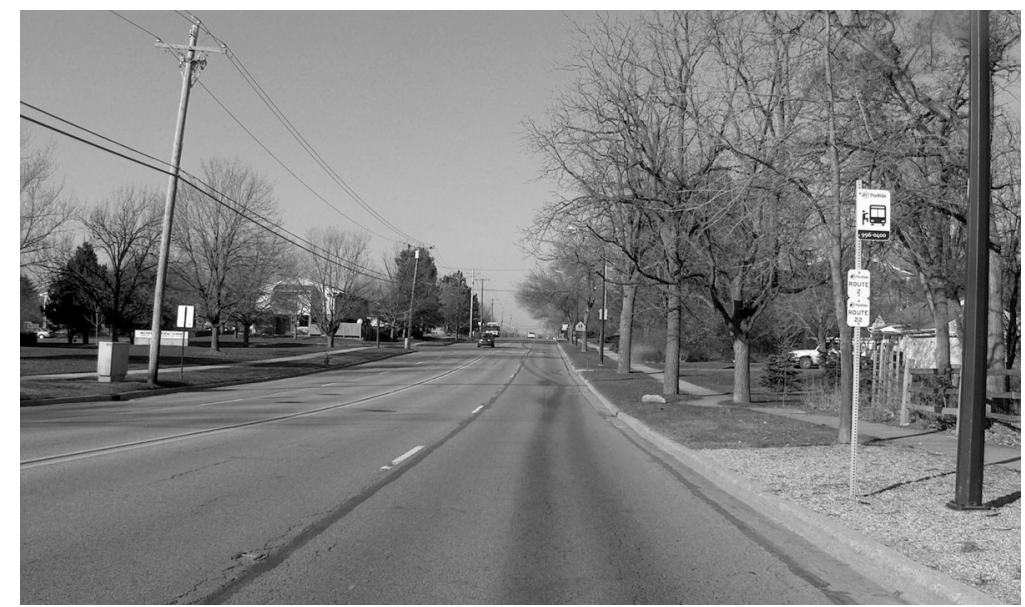

Figure 3. A view of the road used in the experiment. 


\section{Procedure}

Each participant was involved in a single session about 1 hour long. Participants were given instructions at the UMTRI building and then drove the car equipped with the camera system to the test site. An experimenter accompanied the participant, riding in the front passenger seat. A second car, which served as the stimulus car, was driven to the test site by another experimenter. On each of a series of trials, the participant drove the length of the test route, beginning alternately at the north or south end, and attempting to maintain a reasonably constant speed of 25 miles per hour $(40 \mathrm{~km} / \mathrm{hr})$. The participant drove in the right lane until near the end of the route, and then moved into the left lane in preparation to turn onto a designated side street. On each pass, the experimenter in the second car waited until the participant had traveled about $100 \mathrm{~m}$. The experimenter then accelerated the second car to about 35 miles per hour $(56 \mathrm{~km} / \mathrm{hr})$ and began to overtake the participant's car in the left lane.

At the beginning of each trial, the experimenter riding in the front passenger seat of the participant's car instructed the participant to use either the left rearview mirror or the video display to observe the second car approaching from the rear. Participants were told not to stare continuously at the mirror or display, but rather to glance at it when they were able to, without looking away from the forward scene for too long. For safety reasons, all of the standard rearview mirrors were continuously available to the participants on all trials, but they were asked not to look at any mirror or display other than the one designated for a given trial. Participants were asked to indicate, by saying "now," the last moment when they thought it would be safe to initiate a lane change in front of the overtaking car. They were not asked to actually make the maneuver. When the participant responded, the experimenter riding in the front passenger seat pushed a button to mark the event. Differential GPS was used to measure the positions of both vehicles throughout the experiment. Data acquisition systems on both vehicles recorded a variety of information, including position information from the GPS and the moment at which the experimenter pushed the button to indicate that the participant had made a response. 
Each participant drove the length of the route 20 times, in 10 north-south pairs. The first north-south pair was to allow participants to familiarize themselves with the route, and they were not asked to make judgments. The viewing condition (rearview mirror, 1.0-magnification video, or 0.5-magnification video) was the same for both directions of each north-south pair, but was subject to change between pairs. The order of viewing conditions was determined randomly for each participant, with the constraint that each of the three viewing conditions had to appear once in each third of the nine pairs that followed the familiarization pair. 


\section{RESULTS AND DISCUSSION}

For each trial, the distance at which the participant judged it to be safe to initiate a lane-change maneuver was determined from the GPS information recorded by the data acquisition systems on the two cars. This was used as the dependent variable in an analysis of variance in which the independent variables were age group, gender, and viewing condition. Age group and gender did not have significant main effects on distance, although age group was marginal, $F(1,8)=4.35, p=.07$, with younger people tending to choose somewhat shorter distances than older people, as might be expected (mean distances: older $36.0 \mathrm{~m}$, younger $24.1 \mathrm{~m}$ ). The effect of viewing condition was highly significant, $F(2,16)=19.49, p<.0001$. The mean distances for the three viewing conditions are shown in Figure 4. Judgments were strongly affected by the type of display used to observe the overtaking car. The longest distances were obtained with the camera-based display at unit magnification. Distances were substantially shorter with the conventional mirror and with the camera-based display at 0.5 magnification.

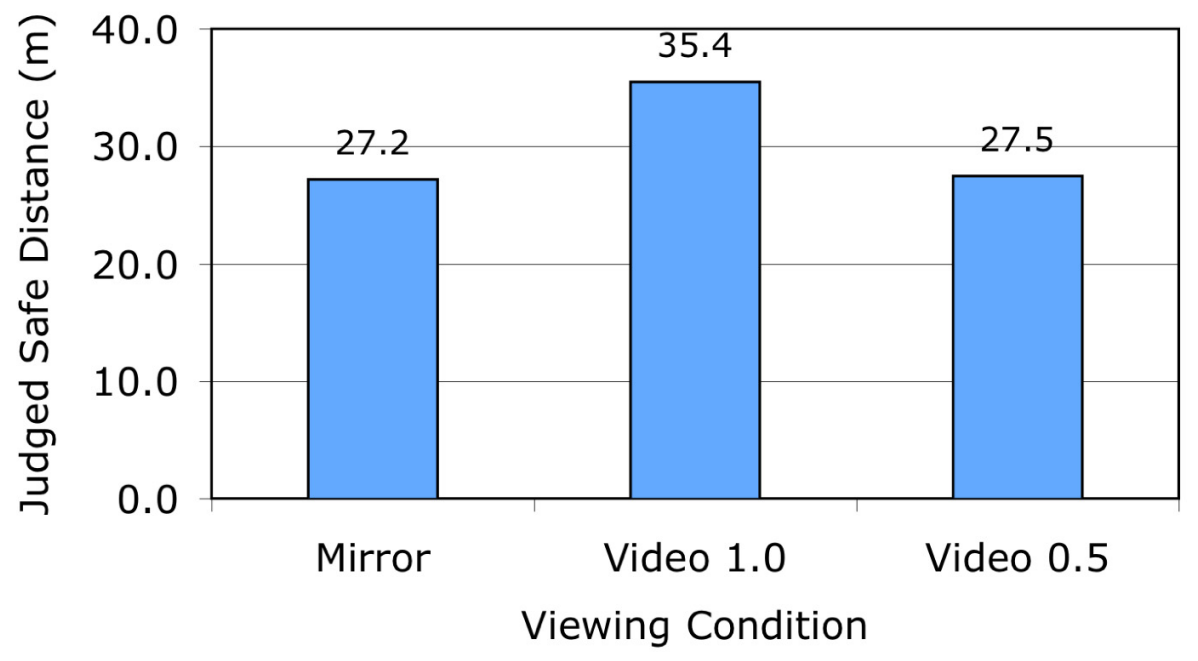

Figure 4. The distances judged to be the minimum safe distances at which to initiate a lane change in front of an overtaking car, by viewing condition.

These results are consistent with results from the earlier study conducted under static conditions (Flannagan et al., 2002). In that study, fixed distances were estimated as $25 \%$ longer when viewed in a rearview mirror than when viewed in a video display. In 
the new results, we have different actual distances that ostensibly meet the same perceptual criterion (safety of a lane change). The relative perceptual increase in the actual distance in the mirror condition $(27.2 \mathrm{~m})$ that would make it equal to the actual distance in the unit-magnification video condition $(35.4 \mathrm{~m})$ is $35.4 / 27.2=1.30$, or $30 \%$, and not very different from the corresponding value of $25 \%$ in the earlier experiment. Both results could be characterized as showing more conservative judgments with a video display than with a mirror, in the sense that they both would seem to predict larger gaps between vehicles during lane changes in which video displays were used. Apparently by coincidence, the other video condition that we used, 0.5 magnification, resulted in judgments that were nearly the same as with the conventional mirror. If performance with a conventional system is taken as a reasonable standard, this result could be used to derive a recommended magnification for video rear vision systems (i.e., 0.5). However, this would be premature given the limited nature of these results. Furthermore, there are conflicting recommendations for magnification of video displays in the literature, including Roscoe's (1984) recommendation of 1.25 and the recommendation by Hicks, Schofield, Tarnow, and Veiseh (1999) of 0.33. Further work is needed to understand how drivers may judge distance in video displays. 


\section{REFERENCES}

Bowles, T. S. (1969). Motorway overtaking with four types of exterior rear view mirror. In International Symposium on Man-Machine Systems, Volume 2, Transport systems and vehicle control (IEEE Conference Record No. 69C58-MMS): Institute of Electrical and Electronic Engineers.

Burger, W. J., Mulholland, M. U., Smith, R. L., \& Sharkey, T. J. (1980). Passenger vehicle, light truck and van convex mirror optimization and evaluation studies: Vol. 1: Convex mirror optimization (DOT HS 805 695). Washington, D.C.: Department of Transportation, National Highway Traffic Safety Administration.

Fisher, J. A., \& Galer, I. A. R. (1984). The effects of decreasing the radius of curvature of convex external rear view mirrors upon drivers' judgements of vehicles approaching in the rearward visual field. Ergonomics, 27(12), 1209-1224.

Flannagan, M. J. (2000). Current status and future prospects for nonplanar rearview mirrors (SAE Technical Paper Series No. 2000-01-0324). Warrendale, Pennsylvania: Society of Automotive Engineers.

Flannagan, M. J., \& Sivak, M. (2003). Framing effects on distance perception in rearvision displays (SAE Technical Paper Series No. 2003-01-0298). Warrendale, Pennsylvania: Society of Automotive Engineers.

Flannagan, M. J., Sivak, M., \& Mefford, M. L. (2002). Distance perception in camerabased rear vision systems (SAE Technical Paper Series No. 2002-01-0012). Warrendale, Pennsylvania: Society of Automotive Engineers.

Flannagan, M. J., Sivak, M., \& Simpson, J. K. (2001). The role of binocular information for distance perception in rear-vision systems (SAE Technical Paper Series No. 2001-01-0322). Warrendale, Pennsylvania: Society of Automotive Engineers.

Hicks, R., Schofield, K., Tarnow, P., \& Veiseh, M. (1999). Panoramic electronic rear vision for automotive applications (SAE Technical Paper Series No. 1999-010655). Warrendale, Pennsylvania: Society of Automotive Engineers.

Kelley, C., R., \& Prosin, D. J. (1969). Motor vehicle rear vision. Santa Monica, California: Dunlap and Associates. 
Mortimer, R. G. (1971). The effects of convex exterior mirrors on lane-changing and passing performance of drivers (SAE Technical Paper Series No. 710543). New York: Society of Automotive Engineers.

Mortimer, R. G., \& Jorgeson, C. M. (1974). Drivers' vision and performance with convex exterior rearview mirrors (SAE Technical Paper Series No. 740961). New York: Society of Automotive Engineers.

Reed, M. P., Lehto, M. M., \& Flannagan, M. J. (2000). Field of view in passenger car mirrors (Report No. UMTRI-2000-23). Ann Arbor: The University of Michigan Transportation Research Institute.

Roscoe, S. N. (1984). Judgments of size and distance with imaging displays. Human Factors, 26(6), 617-629.

Walraven, P. L., \& Michon, J. A. (1969). The influence of some side mirror parameters on the decisions of drivers (SAE Technical Paper Series No. 690270). New York: Society of Automotive Engineers. 